\begin{tabular}{|c|c|c|}
\hline $\begin{array}{c}\text { ISSN 2525-4812 (versão online) } \\
\text { ISSN 2238-7641 (versão impressa) } \\
\text { http://www.revistaterceiramargem.com/ } \\
\text { index.php/terceiramargem/index }\end{array}$ & $\begin{array}{c}\text { Recebido em: 18/6/2019 } \\
\text { Aprovado em: 10/6/2020 } \\
\text { Período de publicação: jan., } 2021\end{array}$ & $\begin{array}{c}\text { Revista Terceira } \\
\text { Margem Amazônia } \\
(\text { v. } 6 \cdot \text { n. especial } 16 \cdot \text { Jan. } 2021)\end{array}$ \\
\hline
\end{tabular}

Como citar o artigo:

ERAZO, R. de L.; COSTA, S. C. F. das C.; COSTA, L. C. P.; SILVA, C. L. da. Análise sociológica de uma feira orgânica do bairro Adrianópolis em Manaus, AM. Revista Terceira Margem Amazônia. v. 6, n. especial 16, p. 163-176, 2021. DOI: http://dx.doi. org/10.36882/2525-4812.2021v6i16.ed.esp.p163-176

\title{
ANÁLISE SOCIOLÓGICA DE UMA FEIRA ORGÂNICA DO BAIRRO ADRIANÓPOLIS EM MANAUS, AM
}

\author{
Rafael de Lima Erazo ${ }^{1}$ \\ Sarah Caroline Ferreira das Chagas Costa ${ }^{2}$ \\ Luiz Cláudio Pires Costa ${ }^{3}$ \\ Chris Lopes da Silva ${ }^{4}$
}

\begin{abstract}
Resumo: As feiras orgânicas são caracterizadas pela presença de produtores certificados, que comercializam produtos in natura e processados no próprio estabelecimento ou de terceiros, também certificados, seguindo as normas da Lei ${ }^{\circ} 10.831 / 2003$. Com isso, buscamos, nesta pesquisa, caracterizar uma feira de alimentos orgânicos em Manaus, AM, assim como os principais atores sociais que constituem esse sistema. A feira, localizada no Bairro de Adrianópolis, Manaus, AM, funciona aos sábados. Por ser um local de comercialização exclusivo de alimentos orgânicos, essa feira constituiu o local de estudo. Dessa forma, a amostra obtida para análise foi de 26 consumidores e 14 produtores. Para a coleta de dados elaborou-se um questionário para os consumidores e outro para os produtores. A coleta de dados foi realizada em outubro de 2019. Os principais produtos comercializados na "Feira do Mapa" são hortaliças, notadamente alface, cebolinha, coentro e pimentão. Esses produtos são expostos de forma tradicional, em bancadas, sendo que a grande maioria é exposta sem selo orgânico de identificação no produto ou embalagem. A "Feira do Mapa" é considerada pequena, possui 18 bancas para venda dos produtos comercializados por associados da Associação dos Produtores de Orgânicos do Estado do Amazonas (Apoam). O perfil dos produtores é assim caracterizado: predominância de mulheres, faixa etária acima de 40 anos, primeiro grau completo, a maioria casados, renda mensal menor que $\mathrm{R} \$ 1.000,00$ reais e a maioria tem entre 2 e 3 filhos. Quanto ao perfil dos consumidores, conclui-se que estes formam um público "cativo" e seleto. A maioria possui alta escolaridade (nível superior), está na faixa de idade acima de 40 anos, declara seu estado civil como casado e renda superior a $\mathrm{R} \$ 3.000,00 /$ mês. Ao se analisarem os atributos mais valorizados pelos consumidores
\end{abstract}

\footnotetext{
1 Engenheiro-agrônomo, M. Sc. em Agricultura no Trópico Úmido, professor da Secretaria de Estado de Educação e Qualidade do Ensino do Amazonas (Seduc), Manaus, AM. E-mail: ra-fa-erazo@hotmail.com

(D) https://orcid.org/0000-0002-6841-1717

2 Engenheira de alimentos, Especialista em Microbiologia Geral, Manaus, AM. E-mail: sarah23caroline@gmail.com (iD) https://orcid.org/0000-0002-7000-5005

3 Advogado, M. SC. em Direito Ambiental, professor da Universidade do Estado do Amazonas, Manaus, AM.

E-mail: luizcpcosta@hotmail.com

(D) https://orcid.org/0000-0002-9035-0084

4 Antropóloga, M. Sc. em Antropologia Social, Manaus, AM. E-mail: pisiiri@gmail.com

(D) https://orcid.org/0000-0002-4627-0896
} 
em relação aos produtos orgânicos, verifica-se que os atributos que os consumidores consideram mais importantes estão relacionados à tríade "saúde, meio ambiente e sabor". No entanto, os consumidores da feira de alimentos orgânicos de Manaus parecem ser motivados mais fortemente por questões pessoais do que por questões ambientais.

Palavras-chave: agricultura familiar, agroecologia, socioeconomia e sustentabilidade.

\title{
A SOCIOLOGICAL ANALYSIS OF AN ORGANICS NEIGHBORHOOD FAIR ADRIANÓPOLIS IN MANAUS, AM
}

\begin{abstract}
Organic fairs are characterized by the presence of certified producers, who sell fresh products and processed in the establishment itself or third parties also certified, following the rules of Law $10.831 / 2003$. With this, we seek in this research to characterize an organic food fair in Manaus-AM, as well as the main social actors that constitute this system. The fair works on Saturdays, is located in the neighborhood of Adrianópolis, Manaus (AM). Being an exclusive place of commercialization of organic foods, this fair in Manaus was the place of study. Thus, the sample obtained for analysis was from 26 consumers and 14 producers. For data collection, a questionnaire was prepared for consumers, and another for producers. Data were collected in October 2019. The main products marketed at the "MAPA fair" are vegetables, notably lettuce, chives, coriander and peppers. The products sold are exposed in a traditional way, in countertops, and the vast majority is exposed without organic seal of identification in the product or packaging. The "MAPA fair" is considered small, having eighteen stalls for sale of products marketed by members of APOAM (Association of Organic Producers of the State of Amazonas). Regarding the profile of the producers, it is concluded that these have a predominance of women, older than 40 years, with completed first degree, are predominantly married, with a monthly income lower than $\mathrm{R} \$ 1,000.00$ reais and that most have between 2 and 3 children. As for the profile of consumers, it is concluded that they form a "captive" and select audience. Most consumers have high education (higher education), are in the age group over 40 years, declares their marital status as married and income higher than $\mathrm{R} \$ 3,000.00$ / month. When analyzing the attributes most valued by consumers in relation to organic products, it is verified that the attributes that consumers consider most important are related to the triad "health, environment and flavor". However, consumers of the Manaus organic food fair seem to be motivated more strongly by personal issues than by environmental issues.
\end{abstract}

Keywords: family farming, agroecology, socioeconomy and sustainability.

\section{Introdução}

As feiras orgânicas são caracterizadas pela presença de produtores certificados, que comercializam produtos in natura e processados no próprio estabelecimento ou de terceiros, também certificados, seguindo as normas da Lei $\mathrm{n}^{\mathrm{o}}$ 10.831/2003 (BRASIL, 2003). A feira livre oferece a possibilidade de o consumidor comparar preços entre diferentes produtores da mesma mercadoria a pequenas distâncias.

O estudo sobre alimentos orgânicos contribui para a reflexão acerca da saúde física humana, da saúde ambiental e da produção com critérios de sustentabilidade. Estudar os consumidores e os produtores orgânicos proporciona a oportunidade de tentar perceber quais distintas motivações influenciam suas decisões de produção e de compra (PIMENTA et al., 2008).

No Brasil, há poucos estudos sobre a oferta de produtos orgânicos em feiras, e o mercado crescente associado à vida saudável pelo consumo de produtos orgânicos fica carente de subsí- 
dios para se orientar na oferta de tais artigos. Essas pesquisas podem contribuir para a criação de estratégias mais adequadas por parte dos participantes da cadeia produtiva de produtos orgânicos. Buscamos, com este trabalho, analisar o perfil e as motivações dos produtores e consumidores de uma feira de alimentos orgânicos em Manaus, AM.

Os alimentos orgânicos têm representado uma das maiores preocupações do homem moderno, que também os associa à sustentabilidade. O alimento orgânico busca atender ao homem em sua necessidade alimentar, não apresentando riscos de contaminação química ou de qualquer outra natureza tóxica, além de produzido de maneira integrada com o ambiente (OLIVEIRA, 2011).

A feira livre oferece a possibilidade de o consumidor comparar preços entre diferentes produtores da mesma mercadoria a pequenas distâncias, contrário ao que acontece entre supermercados, por ficarem distantes uns dos outros. Tal fato dificulta a pesquisa de preços ou a torna inviável para o consumidor. Assim, a feira acaba competindo com o supermercado, porque oferece preços mais acessíveis, e isso agrada ao consumidor (PIMENTA et al., 2008).

Estudar os consumidores de alimentos orgânicos proporciona a oportunidade de tentar descobrir quais distintas motivações influenciam suas decisões de compra (consumo). Tais pesquisas poderão contribuir para a criação de estratégias mais adequadas por parte dos participantes da cadeia produtiva de produtos orgânicos.

Sendo assim, analisaram-se o perfil e as motivações dos produtores (feirantes) e consumidores (clientes) da feira de alimentos orgânicos do "Mapa", em Manaus, AM.

\section{Material e Métodos}

Este artigo é resultado da compilação de um trabalho final, em grupo, da disciplina optativa "Etnoconservação e Percepção Ambiental", do curso de mestrado e doutorado do Programa de Pós-Graduação em Ciências do Ambiente e Sustentabilidade na Amazônia (Ufam).

A cidade de Manaus possui uma feira que comercializa somente produtos orgânicos. Tratase da Feira Orgânica do Ministério de Agricultura, Pecuária e Abastecimento (Mapa), formada pela Associação dos Produtores de Orgânicos do Estado do Amazonas (Apoam). Essa associação é constituída atualmente por cerca de 18 agricultores orgânicos.

A feira funciona exclusivamente aos sábados, a partir das $6 \mathrm{~h}$ e vai até às $12 \mathrm{~h}$, fica localizada no Bairro de Adrianópolis, zona centro-sul do município de Manaus, em um galpão coberto com $400 \mathrm{~m}^{2}$ de extensão, com banheiro e cozinha, cedido pela superintendência do Mapa do Amazonas.

Por ser de comercialização exclusiva de alimentos orgânicos, essa feira constituiu o local de estudo para a realização de um diagnóstico sobre os produtores e consumidores de alimentos orgânicos da região. 
Como universos amostrais foram considerados todos os consumidores e produtores dessa feira orgânica, e a seleção dos entrevistados foi feita por amostragem aleatória simples. Dessa forma, a amostra obtida para análise foi de 26 consumidores e 14 produtores.

O intuito da pesquisa foi expressar o perfil dos consumidores e produtores de produtos orgânicos da feira. Eles foram analisados de forma direta e indireta, por meio de observação, conversação e aplicação de questionários estruturados, buscando-se assim captar o máximo de informações possível sobre o objeto de estudo.

O trabalho envolveu, portanto, a pesquisa de campo, mediante visita ao local do estudo, ocasião em que eram feitas as observações diretas e as entrevistas estruturadas. Os questionários aplicados aos consumidores foram compostos de informações relacionadas aos aspectos idade, sexo, grau de escolaridade, renda, estado civil, se a pessoa sabia o que é produto orgânico, se se preocupavam com a sua própria alimentação e a de seus familiares, se ouviu falar em produtos orgânicos ou se os consumia, caracterizando os aspectos socioeconômicos dos entrevistados e sua percepção em relação aos produtos orgânicos, entre outros. Além desses itens, no questionário, também foram registrados comentários de natureza subjetiva e impressões pessoais acerca de produtos orgânicos.

No caso dos produtores entrevistados, os temas abordados tratavam do perfil da propriedade, como esses produtores se organizam, como se comportam em relação a questões ambientais, área da propriedade, área de cultivo, e a disponibilidade de assistência técnica, entre outros. As entrevistas ocorreram no mês de outubro de 2019.

Para a coleta de dados foi elaborado um questionário para os consumidores contendo 19 questões estruturadas do tipo múltipla escolha e em escalas.

Para os produtores foi elaborado um questionário contendo 23 questões estruturadas do tipo múltipla escolha, discursivas e em escalas. Apesar de extenso, o questionário abordou questões simples, de tal forma que não dificultou ou atrapalhou o feirante e o consumidor. Assim, foi possível entrevistar os feirantes ao mesmo tempo em que eles estavam trabalhando.

Os dados obtidos foram codificados, dispostos em planilha eletrônica em forma de banco de dados (Excel), distribuídos em gráficos e analisados qualitativa e quantitativamente. Antecedendo a aplicação dos questionários foi solicitada oficialmente autorização prévia do presidente da Apoam, e somente após essa etapa é que foi iniciada a aplicação dos questionários.

\section{Perfil da feira de alimentos orgânicos do Mapa}

Os principais produtos comercializados na feira do Mapa são hortaliças, notadamente alface, tomate, cebolinha, coentro, pimentão, cenoura, cebola, couve, dentre outros produtos agrícolas, como batata-doce, feijão, citros, mamão e ovos. Ao todo foram registrados 39 produtos comercializados na feira.

Os produtos comercializados são expostos de forma tradicional, em bancadas, cuja grande maioria é exposta sem selo orgânico de identificação no produto ou embalagem. Apenas alguns produtos são embalados e apresentam o selo orgânico com identificação da propriedade produtora. 
Outros aspectos observados foram: 1) a diversidade de produtos ofertados; 2) a estrutura física do local de realização das feiras, sendo estas bastante atrativas e organizadas. Pode-se dizer que esses espaços são de fundamental importância para o desenvolvimento de uma nova cultura de consumo, mais consciente e voltada para melhor qualidade de vida e uma agricultura mais sustentável.

Percebe-se que as hortaliças são as principais culturas produzidas em sistemas orgânicos, tanto na região de Manaus como na região de Goiânia, GO, e na região de Bauru, SP, possivelmente pela facilidade de adaptação da produção do sistema convencional para o orgânico (DULLEY et al., 2003).

A feira de alimentos orgânicos do Mapa é considerada pequena, com apenas 18 bancas para venda dos produtos comercializados por associados da Apoam. A feira é frequentada por aproximadamente 200 consumidores aos sábados.

As feiras orgânicas são mercados distintos daqueles convencionais, já que elas seguem normas estabelecidas por diferentes atores sociais. Ou seja, os agricultores que participam desse tipo de mercado foram incentivados pelos fundamentos da Agroecologia e seguem regras estabelecidas por órgãos de fiscalização para que possam desfrutar da feira (MARIANO NETO, 2006).

Os produtos orgânicos em exposição para venda são provenientes da agricultura familiar, e a comercialização é realizada por membros da família, como o próprio agricultor, esposa e filhos. Essa forma de comercialização direta permite a otimização e o aproveitamento da mão de obra familiar e elimina a figura dos atravessadores, e isso possibilita uma redução dos preços ao consumidor e pode melhorar a margem de lucro dos produtores.

Para se comercializar produtos orgânicos, a obtenção de certificação é necessária. Entre os feirantes entrevistados, nenhum possui certificação, sendo que o certificado é expedido pelo Instituto Biodinâmico (IBD). O que eles apresentam é uma declaração. Uma justificativa apresentada pelos produtores que não possuem a certificação está relacionada às normas exigidas pelas instituições certificadoras para a produção e comercialização de produtos orgânicos. É necessário que a propriedade passe por uma adaptação, e na maioria das vezes isso exige investimento financeiro por parte dos produtores.

A declaração que garante que os produtos são orgânicos é concedida pelo Mapa depois de uma série de fiscalizações na propriedade rural. Essa fiscalização tem o objetivo de averiguar se os agricultores seguem as exigências da produção orgânica, o que inclui o não uso de produtos químicos (adubos e agrotóxicos). Para os produtores, a motivação para substituir o uso de venenos e adubos químicos é a compreensão de que tais produtos causam mal à saúde das pessoas e ao meio ambiente.

Outros trabalhos investigativos sobre o assunto também apontaram alguns aspectos semelhantes aos observados durante este estudo. A comercialização de produtos orgânicos por meio de feiras, além de proporcionar alimentos de boa qualidade, que beneficiam a saúde das famílias, incentiva a utilização de boas práticas no cuidado com o meio ambiente e a sustentabilidade ambiental por parte dos produtores. 


\section{Produtores entrevistados}

Verificou-se que, entre os produtores entrevistados: $57,1 \%$ são do sexo feminino e $42,9 \%$ são do sexo masculino, o que mostra certo equilíbrio de gênero, com leve predominância de mulheres entre os produtores-expositores.

Com relação à faixa etária: verificou-se que 50\% apresentam mais de 40 anos, seguidos por $35,7 \%$ entre a faixa etária de 30 a 40 anos, o que revela uma amostragem composta por um público mais maduro, já que apenas 14,3\% apresentavam a faixa etária de 20 a 30 anos.

Quanto ao grau de escolaridade, 14,3\% têm primeiro grau incompleto, 50\% têm primeiro grau completo e 35,7\% têm segundo grau completo. Quanto ao número de filhos: $35,7 \%$ possuem mais de três filhos, 35,7\% têm entre dois e três filhos, $21,4 \%$ têm apenas um filho e 7,1\% não têm filhos. Com relação ao estado civil dos produtores: $71,4 \%$ são casados e $28,6 \%$ são solteiros.

Conforme os dados coletados relacionados à renda familiar: $57,1 \%$ dos produtores entrevistados responderam que têm renda mensal menor que $\mathrm{R} \$ 1.000 ; 28,6 \%$ têm renda entre $\mathrm{R} \$$ 1.000 e $\mathrm{R} \$ 2.000$, e $14,3 \%$ entre $\mathrm{R} \$ 2.000$ e $\mathrm{R} \$ 3.000$.

\section{Perfil da propriedade dos produtores}

A maior parte das propriedades dos produtores de orgânicos entrevistados na feira são constituídas de áreas com mais de 3 ha (57\%). Cerca de 21,4\% são propriedades entre 1 e 3 hectares e $21,4 \%$ são propriedades com menos de 1 hectare, demonstrando assim a prática desse tipo de agricultura por produtores familiares.

Quanto ao tamanho da área de produção, cerca de 28,5\% possuem área menor que 1 ha, $50 \%$ de 1 a 3 ha e $21,5 \%$ de mais que 3 ha.

\section{Dificuldades encontradas pelos produtores}

As dificuldades encontradas variam de produtor para produtor, porém as queixas são constantes, sendo basicamente as mesmas já relatadas por diversos pesquisadores (DULLEY et al., 2003). Incluem-se as dificuldades associadas aos temas: assistência técnica, obtenção de insumos, problemas relativos ao mercado e crédito rural. O que permite inferir que uma política pública eficiente de incentivo à produção orgânica é necessária, visto que existe um número crescente de agricultores interessados nesse tipo de produção em vários locais do País.

As dificuldades na produção de orgânicos apontadas pelos produtores foram: 1) a obtenção de certificação; 2) dificuldade na aquisição de insumos; 3) dificuldade com a mão de obra; 4) dificuldade em obter assistência técnica; 5) perdas na produção; 6) sazonalidade da produção; 7) devolução de parte da produção; 8) controle de pragas; e 9) mecanização. Além disso, todos os produtores relataram possuir algum problema com pragas, sendo as formigas as mais frequentes, presente em cerca de $70 \%$ das áreas dos produtores. 


\section{Valorização e proteção do produtor}

O fato de os próprios agricultores comercializarem seus produtos contribui para a valorização do trabalho, uma vez que o atravessador sai de cena e entra o produtor/comerciante. A venda direta faz com que o consumidor sinta maior segurança ao adquirir o produto, já que o responsável pela qualidade dele está lhe garantindo isso pessoalmente.

Além disso, esse mercado, que tem despontado como promissor, concede oportunidade aos produtores que não têm acesso a outro meio para comercializar seus produtos. Outro dado a ser ponderado é a existência de clientes fiéis, percebidos pelos feirantes. Em média, cada feirante possui de 14 a 15 clientes que adquirem seus produtos semanalmente. São clientes que acabam estabelecendo laços de amizade com o comerciante. A proteção ao produtor rural também foi um aspecto valorizado pelos pesquisados, sendo essa valorização consistente com as recomendações do Mapa (BRASIL, 1999).

\section{Preocupação dos produtores com as questões ambientais}

Todos os produtores entrevistados informaram que o principal motivo pela opção pelo sistema orgânico de produção é a preocupação com a saúde da própria família e do consumidor, além da oportunidade de diversificação da produção.

\section{Comercialização dos produtos orgânicos pelos produtores}

Com referência à comercialização, $35 \%$ dos feirantes relataram comercializar também em outro espaço, como, por exemplo, na feira da Expoagro. Cerca de 82\% dos feirantes afirmaram que toda a sua produção é comercializada; os que afirmaram não comercializar totalmente sua produção relataram que consomem a parte não comercializada.

Quanto às dificuldades de comercialização, mais da metade dos feirantes entrevistados afirmaram enfrentar algum tipo de restrição ou obstáculo à comercialização.

A penetração de mercado foi uma dificuldade encontrada em Bauru por Dulley et al. (2003). Também foram citados como problemas dos feirantes de Goiânia o transporte e a padronização dos produtos, o que pode indiretamente levar a maior dificuldade de aceitação do produto orgânico.

\section{Uso da água na produção de orgânicos}

Todos os produtores afirmaram que utilizam água de boa qualidade, no entanto nenhum deles realiza análise química da água. A captação é diversificada, mudando de produtor para produtor, sendo proveniente de rios dentro e fora das propriedades, nascentes, poços, cisternas e represas. Esses resultados indicam que a qualidade da água percebida pode ser bem diferente da qualidade da água real, visto que nenhum dos produtores possui resultados de análises químicas para controle. 


\section{Origem das sementes e mudas empregadas no sistema de produção orgânica}

Com relação à origem das sementes e mudas empregadas nos cultivos declarados como orgânicos ou em transição verificou-se que nenhum produtor mencionou produzir suas próprias mudas e sementes, $70 \%$ são comprados de produção não orgânica, aquisição no mercado local, o que pode indicar uma eventual planta de origem não orgânica. Cerca de 30\% obtém sementes orgânicas por intermédio de amigos e de órgãos de pesquisa, como a Empresa Brasileira de Pesquisa Agropecuária (Embrapa) e o Instituto Nacional de Pesquisas da Amazônia (Inpa).

\section{Quanto à busca de informaç̃̃es sobre produção orgânica}

Cerca de $80 \%$ dos feirantes entrevistados buscam qualificação sobre a produção de orgânicos por meio de cursos presenciais, informações disponíveis na internet, congressos na área de agroecologia, apostilas e palestras.

\section{Motivo dos produtores para produzir alimentos orgânicos}

Os produtores entrevistados responderam que produzem alimentos orgânicos porque é mais saudável, protege o meio ambiente e conserva o solo, contribuindo assim para melhor qualidade de vida, protegendo as gerações futuras.

\section{Motivo de fazer parte da Apoam e a sua importância}

Quando questionados sobre o motivo de participar da Apoam, eles salientaram principalmente o aspecto do crescimento profissional, por trabalhar em coletivo, e também citaram o aspecto financeiro, todos possuem retorno econômico satisfatório.

Para todos os produtores entrevistados, as vendas aos sábados na feira são vantajosas, pois é certa a comercialização de seus produtos, e em um período curto de tempo a maioria dos produtos é vendida, proporcionando assim um bom retorno financeiro.

\section{Dificuldades para obtenção da certificação}

Para os produtores entrevistados, a maior dificuldade de se obter a certificação é a burocracia, de modo geral, e a falta de incentivo do governo.

\section{Local de origem dos produtores}

Todos os produtores entrevistados residem no mesmo local onde produzem, dentre os quais: Assentamento Tarumã-Mirim, Ramal do Brasileirinho, Pau-Rosa, Ramal da Placa (AM-010) entre outros. Áreas muito próximas ao perímetro urbano de Manaus ou em áreas de transição periurbanas com acesso por estradas.

\section{Consumidores entrevistados}

Verificou-se que, entre os consumidores entrevistados: $53,8 \%$ são do sexo feminino e $46,2 \%$ são do sexo masculino, o que mostra uma leve predominância de mulheres entre os consumidores 
potenciais de produtos orgânicos, o que não surpreende, já que no Brasil as mulheres respondem por cerca de $70 \%$ das decisões de compra e priorizam produtos saudáveis, pois se preocupam com a alimentação da família (CERVEIRA; CASTRO, 1999a). Os valores aqui obtidos são coerentes com os verificados por Darolt (2004) em estudo realizado em Curitiba, PR, e por Cerveira e Castro (1998) em estudos realizados em São Paulo, SP, e também com os obtidos por Francisco et al. (2009), em estudo realizado em São Paulo que mostra que $71,2 \%$ dos consumidores são mulheres.

O gênero dos consumidores analisados não está associado a nenhuma variável investigada, revelando que não existe associação entre o gênero do consumidor e a disposição em pagar preços superiores por alimentos orgânicos, assim como também não existe associação entre o gênero desses consumidores e a frequência de compra de alimentos orgânicos.

Com relação à faixa etária, verificou-se que: 53,8\% apresentam mais de 40 anos, seguidos por $34,6 \%$ entre a faixa etária de 30 a 40 anos, o que revela amostragem composta por um público mais maduro e com isso se estabelecem outras perspectivas com relação a uma alimentação saudável, e também por terem tido a oportunidade de vivenciarem uma época em que se consumiam alimentos mais naturais. Apenas $11,5 \%$ dos consumidores entrevistados apresentavam entre 20 e 30 anos.

A faixa etária dos consumidores investigados está associada à frequência de compra de alimentos orgânicos, ou seja, os consumidores com maior faixa etária compram alimentos orgânicos mais frequentemente. Contudo, a faixa etária dos consumidores não está relacionada à disposição em pagar preços superiores por esses alimentos.

\section{Grau de escolaridade e estado civil dos consumidores}

Quanto ao grau de escolaridade, verificou-se que: 11,5\% têm doutorado, 19,2\% têm mestrado, $34,6 \%$ têm especialização, 7,7\% têm até o curso superior completo, 19,2\% têm até o curso superior incompleto e $7,7 \%$ têm até o segundo grau completo. O perfil aqui obtido se assemelha ao obtido por Castro (1998) em um estudo realizado em São Paulo, SP, e por Cuenca et al. (2007), no Rio Grande do Norte, e ao relatado por Francisco et al. (2009) em estudo realizado em São Paulo, onde foi observado que a maioria dos entrevistados possuía nível superior completo ou pós-graduação.

O elevado nível de escolaridade predominante entre os pesquisados pode estar relacionado a mudanças culturais, sendo que a melhor instrução pode propiciar a esses indivíduos uma visão de longo prazo sobre os efeitos dos alimentos no organismo humano (BLACKWELL et al., 2005). Contudo, deve ser considerada a localização das feiras como fator que favorece o acesso de vários indivíduos, uma vez que estas podem ocorrer também próximas aos locais de trabalho ou de trânsito habitual desses consumidores.

Com relação ao estado civil, observou-se que: $30,7 \%$ eram solteiros e $61,5 \%$ casados, o que mostra que também os solteiros se preocupam com a sua qualidade de vida e saúde. Cerca de $3,8 \%$ são divorciados e 3,8\% são viúvos. 
Os pesquisados, em sua maioria, são casados, o que denota que suas compras atendem a um grupo familiar e não à preferência individual. Apesar desse dado, as transformações da família tradicional impedem que essas indicações sejam consideradas conclusivas acerca dos frequentadores das feiras de orgânicos.

\section{Renda familiar dos consumidores}

Conforme os dados coletados relacionados à renda familiar, verificou-se que: $46,1 \%$ dos entrevistados responderam que têm uma renda mensal acima de 3 mil reais, 38,5\% entre 2 mil reais e 3 mil reais e $15,4 \%$ entre mil reais e 2 mil reais. Isso mostra que o consumo de produtos orgânicos, bem como a predisposição ao seu consumo, está relacionado às pessoas de maior poder aquisitivo. O perfil aqui obtido é coerente ao observado por Rucinski e Brandenburg (2000), que verificaram em Curitiba, $\mathrm{PR}$, que o consumo de alimentos orgânicos está relacionado às pessoas com maior poder aquisitivo. Também, os dados obtidos para a renda familiar, neste estudo, são coerentes ao obtido por Cerveira e Castro (1998) em São Paulo, Darolt (2004) em Curitiba e Francisco et al. (2009), que observaram renda predominante de $\mathrm{R} \$ 3.000,00$ a $\mathrm{R} \$ 4.999,00 \mathrm{e}$ acima de R $\$ 8.000,00$.

Em relação à faixa de renda familiar dos consumidores entrevistados, esta se encontra associada à frequência de compra de alimentos orgânicos, pois, dos 26 consumidores entrevistados na feira, 12 apresentam renda mensal de mais de $\mathrm{R} \$ 3.000,00$, e desses, 7 compram na feira todo sábado.

\section{Preocupação do consumidor com sua alimentação e da família}

Quando foram questionados sobre a preocupação com a sua alimentação e de sua família, cerca de $69,2 \%$ responderam que concordam totalmente com a preocupação com a sua alimentação e da sua família e $26,9 \%$ concordaram sobre a temática da segurança alimentar abordada. Citaram que essa preocupação é por terem uma dieta mais equilibrada em nome de uma melhor qualidade de vida e saúde e por acharem que os produtos orgânicos são uma alternativa de consumir produtos naturais. Apenas 3,8\% dos consumidores discordaram.

\section{Frequência dos consumidores quanto à compra de alimentos orgânicos em feiras}

Quanto à frequência de consumo de produtos orgânicos em feiras, cerca de 53,8\% responderam que toda semana compram alimentos orgânicos em feiras. Cerca de 15,4\% compram a cada quinzena, $26,9 \%$ compram eventualmente e $3,8 \%$ estavam comprando pela primeira vez.

Foi possível observar que existe um fluxo significativo de consumidores que vão à feira semanalmente. Apesar de ser pequeno o número quando comparado com as feiras convencionais, os feirantes afirmam que é uma quantidade significativa por se tratar de uma feira com produtos específicos. Além disso, a feira não realiza propagandas, seu principal meio de divulgação é o "boca a boca". 
Cabe considerar, porém, que a localização da feira pode ter influenciado a seleção da amostra pesquisada, por se localizar em região considerada nobre. A localização da feira não é impedimento para a aquisição de produtos orgânicos, segundo os pesquisados, mas há influência desse aspecto notadamente nos indivíduos que realizam compras com frequência semanal. A conveniência da localização da feira é um fator que parece influenciar, inclusive, o nível de satisfação dos pesquisados com os produtos adquiridos.

\section{Motivos de consumo}

Os motivos determinantes do consumo elencados pelos entrevistados são semelhantes aos elencados em outros estudos de perfil do consumidor. Preponderaram os fatores de busca por alimentos mais saudáveis, para melhoria da qualidade de vida, por entenderem ser um produto natural, para contribuir com a preservação da saúde, entre outros.

\section{Grau de confiança e satisfação dos consumidores}

Cerca de $11,5 \%$ do público-alvo confiam totalmente nos produtos orgânicos vendidos na feira e $65,4 \%$ confiam. Já $15,4 \%$ declararam não confiar e nem desconfiar e 7,7\% desconfiam. Esses valores podem ser atribuídos ao fato levantado por eles, que é a falta de informação nos locais de venda e pela falta de informações rotulares.

Em relação à satisfação com o produto adquirido, os pesquisados demonstraram indecisão quanto a deixar de consumi-los quando não satisfeitos. Isto pode estar relacionado ao pouco conhecimento desses produtos e, por consequência, à falta de parâmetros para uma avaliação precisa da sua qualidade e/ou adequação.

\section{Quanto à contribuição da produção de alimentos orgânicos para a proteção das gerações futuras}

A contribuição da produção de alimentos orgânicos para a proteção das gerações futuras também foi um aspecto que obteve importante concordância dos pesquisados. Diante disso, pode-se inferir que há uma percepção acentuada desses indivíduos quanto à amplitude do conceito de desenvolvimento sustentável tal como proposto pela Organização das Nações Unidas (ONU).

\section{Comportamento dos consumidores acerca das variáveis socioambientais}

Ao se observar o comportamento dos pesquisados em relação às variáveis ambientais, constatou-se que eles consideram relevantes todos os indicadores socioambientais sugeridos nas entrevistas. De modo geral, os consumidores foram mais afirmativos quanto à contribuição do consumo de orgânicos como proteção às gerações futuras e como forma de evitar a contaminação dos solos. A redução do aquecimento global também foi relacionada à produção orgânica, porém de modo menos afirmativo que as demais associações. 


\section{Quanto à disposição para pagar a mais pelos produtos orgânicos em compara- ção aos produtos convencionais}

Apesar de os preços dos produtos orgânicos serem mais elevados, os pesquisados demonstraram disposição para pagar mais por eles, em percentuais que variaram de $5 \%$ até mais de $50 \%$ pelos produtos, em função da preocupação com a própria saúde e o meio ambiente. A concordância com esse aspecto ocorreu independentemente do nível de escolaridade e da renda familiar.

Essa referência ao preço é contrária à encontrada por Darolt (2004), que atribuiu o baixo consumo de produtos orgânicos, entre outros fatores, ao seu preço mais elevado. Pode ter havido alguma alteração na percepção do consumidor ou ser esta uma posição inerente ao mercado pesquisado e sua localização.

\section{Quanto ao fator que mais influencia na compra de alimentos orgânicos}

O atributo mais referido pelos pesquisados como fator de influência na compra foi a garantia. No entanto, o conceito de garantia parece não estar relacionado à certificação, uma vez que esta não foi considerada como fator de suficiente confiabilidade.

Dessa forma foi possível perceber que os consumidores de produtos orgânicos da cidade de Manaus possuem grande fidelização com os produtores e percebem a importância desses produtos para o meio ambiente e para a saúde de quem os consomem. Os produtores necessitam ainda transmitir mais informações aos seus consumidores sobre as vivências e práticas com os agroecológicos, seja por meio de panfletos, banners, até mesmo promoção de palestras para o público em geral, possibilitando, assim, a conquista de mais consumidores.

\section{Conclusão}

A pesquisa mostrou que, na feira, os principais produtos comercializados são os produtos in natura, do grupo das hortaliças, notadamente as folhosas.

Quanto ao perfil dos produtores de alimentos orgânicos, conclui-se que estes apresentam predominância de mulheres, faixa etária de mais de 40 anos, escolaridade primeiro grau completo, a maior parte casados, com dois a três filhos, e renda mensal menor que R\$1.000,00.

Quanto ao perfil dos consumidores de alimentos orgânicos, conclui-se que eles formam um público "cativo" (consumidores frequentes) e seleto. A maioria possui alta escolaridade (nível superior), está na faixa de idade superior a 40 anos, declara seu estado civil como casado e renda superior a $\mathrm{R} \$ 3.000,00 /$ mês.

Ao se analisar os atributos mais valorizados pelos consumidores em relação aos produtos orgânicos, verifica-se que os atributos que os consumidores consideram mais importantes estão relacionados à tríade "saúde, meio ambiente e sabor". No entanto, os consumidores da feira de alimentos orgânicos de Manaus parecem ser motivados mais fortemente por questões pessoais (do indivíduo e sua família) do que por questões ambientais (proteção dos recursos naturais e outros), com destaque para a motivação de consumo de alimentos considerados mais saudáveis 
e saborosos. Ainda assim, os consumidores de Manaus percebem a importância desses produtos para o meio ambiente e para a saúde dos produtores. Observou-se que o fato de o produto orgânico não conter agrotóxicos, os quais prejudicam a saúde das pessoas e contaminam o meio ambiente, é o grande diferencial desse tipo de produto.

O grupo de pessoas que consome produtos orgânicos está emergindo, e os principais entraves para o seu aumento são a baixa oferta dos produtos e a falta de informações em locais de venda e nos rótulos.

\section{Referências}

BLACKWELL, R.; MINIARD, P.; ENGEL, J. Comportamento do consumidor. São Paulo: Pioneira Thompson Learning, 2005.

BRASIL. Ministério da Agricultura e do Abastecimento. Instrução normativa n. 007, de 17 de maio de 1999. Estabelece as normas de produção, envase, distribuição, identificação e de certificação de qualidade para produtos orgânicos de origem animal e vegetal. Diário Oficial [da] União, Brasília, 19 maio 1999. Seção 1, p. 11-14.

BRASIL. Lei $\mathbf{n}^{\mathbf{0}} \mathbf{1 0 8 3 1}$, de 23 de dezembro de 2003. Dispõe sobre a agricultura orgânica e dá outras providências. 2003. Disponível em: http://www2.ufrb.edu.br/cecane/projeto-mais-mercado/category/11-legislacao?download=28:1-lei-n-10-831-de-23-de-dezembro-de-2003. Acesso em: 13 ago. 2020.

CERVEIRA, R.; CASTRO, M. C. Perfil sócio-econômico dos consumidores de produtos orgânicos da cidade de São Paulo. Boletim Agroecológico, ano 3, n. 12, p. 7, 1998.

CUENCA, M. A. G.; MOREIRA, M. A. B.; NUNES, M. U. C.; MATA, S. S. da; GUES, C. G. M.; BARRETO, M. de F. P.; LOPES, V. R. M.; PAZ, F. das C. A.; SILVA, J. R. da; TORRES, J. F. Perfil do consumidor e do consumo de produtos orgânicos no Rio Grande do Norte. Aracaju: Embrapa Tabuleiros Costeiros, 2007. 17 p. (Embrapa Tabuleiros Costeiros. Documentos, 125).

DAROLT, M. R. O papel do consumidor no mercado de produtos orgânicos. 2004. Disponível em: http://www.planetaorganico.com.br/trabdarolt1.htm. Acesso em: 03 out. 2020.

DULLEY, R. D.; SILVA, V.; ANDRADE, J. P. S. Estrutura produtiva e adequação ao sistema de produção orgânico. Informações Econômicas, v. 33, n. 11, nov. 2003.

FRANCISCO, E. S.; MOURA, F. A.; ZANON, R. S.; MARINHO, B. L. Comportamento do consumidor na compra de produtos orgânicos. In: SEMINARIOS EM ADMINISTRAÇÃO, 12., 2009, São Paulo. Anais... São Paulo: SEMEAD, 2009.

MARIANO NETO, B. Abordagem territorial e enfoques agroecológicos no agreste/brejo paraibano: desenhos, arranjos e relações. 2006. 208 f. Tese (Doutorado em Sociologia) - Universidade Federal da Paraíba, Centro de Ciências Humanas, Letras e Artes, João Pessoa-PB; Universidade Federal de Campina Grande, Centro de Humanidades, Campina Grande-PB.

OLIVEIRA, A. D. Produtos orgânicos: fatores determinantes de comportamento de compra de consumidores em supermercados da região sul do Município de Belo Horizonte - MG. 2011. Dissertação (Mestrado) - Faculdade Novos Horizontes, Belo Horizonte. 
PIMENTA, M. L.; MELO, D. C.; VILAS BOAS, L. H. B.; SILVA, A. L.; SETTE, R. S. Segmentação por valores: conhecendo melhor o mercado consumidor de orgânicos da cidade de Uberlândia. In: ENCONTRO DA ASSOCIAÇÃO NACIONAL DE PÓS-GRADUAÇÃO E PESQUISA EM ADMINISTRAÇÃO, 2008, Rio de Janeiro. Anais... Rio de Janeiro: ANPAD, 2008.

RUCINSKI, J.; BRANDENBURG, A. Consumidores de alimentos orgânicos em Curitiba. s.l.: Associação Nacional de Pós-Graduação e Pesquisa em Ambiente e Sociedade (ANPPAS), 2000. 